\title{
Mechanistic Aspects of Alloxan Diabetogenic Activity: A Key Role of Keto-Enol Inversion of Dialuric Acid on Ionization
}

\author{
Małgorzata Czerwiñska, Adam Sikora, Piotr Szajerski, Jan Adamus, Andrzej Marcinek,* and \\ Jerzy Gębicki* \\ Institute of Applied Radiation Chemistry, Technical University of Lodz, Zeromskiego 116, 90-924 Lodz, Poland \\ Paweł Bednarek \\ Department of Chemistry, University of Fribourg, CH-1700 Fribourg, Switzerland
}

\begin{abstract}
The inversion of the keto-enol stability order of dialuric acid on ionization was calculated and verified experimentally. The radical cations in both forms were characterized. The spectrum of the keto form was observed upon direct ionization of dialuric acid under matrix conditions, whereas the enol form was formed upon a sequential electron - proton - proton attachment to alloxan under acidic aqueous condition. Facilitation of the one-electron oxidation of dialuric acid upon its enolization can result in a more effective formation of superoxide radical anion in the process of its auto-oxidation. This process is discussed in reference to the alloxan diabetogenic action. Both neutral keto and enol forms are energetically close, and under favorable conditions, the auto-oxidation of dialuric acid could involve participation of the enol form.
\end{abstract}

\section{Introduction}

The pyrimidine derivative 2,4,5,6[1H,3H]-pyrimidinetetrone known as alloxan (A) has been widely used to induce diabetes mellitus in animals for many decades. ${ }^{1,2}$ Among chemical compounds that rapidly and selectively damage pancreatic $\beta$-cells, alloxan exibits the most potent toxicity; hence the mechanism of its action has been the subject of many investigations.

There is evidence that redox cycling involving alloxan and its reduction product, dialuric acid (DA) initiates an intracellular generation of reactive oxygen species. ${ }^{2-8}$ One possible mech-

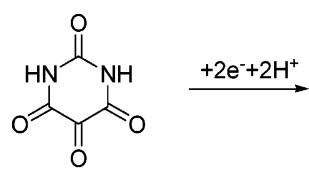

A

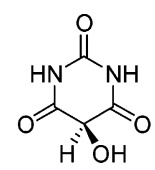

DA anism of alloxan activity assumes its reduction to dialuric acid, the process that can be effectively enhanced by physiological reagents such as NAD(P)H and GSH and by enzymatic means by the thioredoxin/NADPH-thioredoxin reductase or thioltransferase systems. ${ }^{9-16}$ The subsequent oxidative decomposition of dialuric acid is thought to account for alloxan toxicity in the $\beta$-cells through the oxidation stress. ${ }^{17-19}$

Auto-oxidation of the dialuric acid has been shown to generate $\mathrm{O}_{2}{ }^{\bullet-}, \mathrm{H}_{2} \mathrm{O}_{2}$, and, in the presence of suitable catalyst, ${ }^{\bullet} \mathrm{OH} \cdot{ }^{5,8,20}$ It is likely that the potent catalytic effect of transition metals on dialuric acid auto-oxidation is initiated by electron transfer from dialuric acid to metal. ${ }^{7}$ Besides the intermediate formation of one-electron oxidized product, dialuric acid radical cation,

* Corresponding authors. A.M., tel, +48-42-6313096; fax, +48-426365008; e-mail, marcinek@p.lodz.pl. J.G., tel, +48-42-6313171; fax, +4842-6365008; e-mail, jgebicki@p.lodz.pl. the auto-oxidation process involves also semiquinone type alloxan radical, another easily oxidized species., ${ }^{9,13,21-24}$

Superoxide dismutase and catalase, hydroxyl radical scavengers and metal chelators inhibited to some extent the diabetogenic effect of alloxan ${ }^{25-27}$ which indicates that reactive oxygen species (ROS) participate in the overall auto-oxidation of dialuric acid. ${ }^{9,20}$ According to the proposed mechanisms, dialuric acid auto-oxidation can occur via different pathways, such as oxidation of dialuric acid by molecular oxygen, an autocatalytic reaction between the oxidized and reduced forms of pyrimidine or a superoxide dependent chain.

Uncatalyzed auto-oxidation, especially by molecular oxygen, is known to be a very slow process. ${ }^{8,20}$ Although the autooxidation of dialuric acid has been extensively studied, the exact mechanism of this reaction is not clearly understood. The present study was undertaken to elucidate in detail the mechanism of one-electron oxidation of dialuric acid that should provide a basis for understanding how this compound exerts its cytotoxity.

We have recently shown that for certain classes of molecular ions, the products of one-electron oxidation, the inversion of the stability order of tautomeric systems on ionization is one of the unique features. Inversion of the keto-enol stability order was calculated and verified experimentally for many systems. ${ }^{28,29}$ Enol radical cations are thermodynamically favored over their corresponding keto forms because it takes less energy to remove an electron from the $\pi$-orbital of an enol than from the n-orbital of a ketone. In addition, the structural changes of enols upon ionization are more pronounced than in the ketotautomers, where ionization predominantly affects the carbonyl moiety, and have a bigger effect on the stability of the ionized molecule. In principle, an approach of radical cation tautomerization can be expanded for radical cations generated from dialuric acid. In this paper we have attempted to apply a concept of radical cation tautomerization to dialuric acid auto-oxidation process and to discuss a potential involvement of the dialuric acid enol form. 


\section{Experimental Section}

2.1. Compounds. Alloxan (A), 2-methyltetrahydrofuran (MTHF), 2-chlorobutane and KSCN were obtained from SigmaAldrich. KBr, 2-propanol, perchloric acid and sodium hydroxide were from POCH (Poland).

Preparation of Dialuric Acid Solutions (DA). To a degassed solution of alloxan monohydrate $(120 \mathrm{mg}$, Aldrich) in $20 \mathrm{~mL}$ of deionized water was added $200 \mathrm{mg}$ of sodium dithionite (Aldrich), and the flask was stoppered with a rubber septum. The solution was stirred under an argon stream for $15 \mathrm{~min}$ and then left to allow sedimentation of a precipitate. The resulting saturated aqueous solution of dialuric acid (DA) was transferred (under argon pressure, through a cannula equipped with a small paper filter) to another flask containing degassed solvent. DA was then extracted to the solvent by shaking the flask. The concentration of DA in the resulting solution was determined spectrophotometrically $\left(\lambda_{\max }=275 \mathrm{~nm}, \epsilon_{\max }=1.66 \times 10^{4} \mathrm{M}^{-1}\right.$ $\left.\mathrm{cm}^{-1}\right){ }^{24}$

Preparation of 1-Butyl-3-methylimidazolium Hexafluorophosphate $\left(\mathrm{BMIM}^{+} \mathrm{PF}_{6}{ }^{-}\right)$. The mixture of 1-methylimidazole (41 g, 0.5 mole, Aldrich) and 1-chlorobutane ( $47 \mathrm{~g}, 0.51$ mole, Aldrich) was vigorously stirred and heated at $75{ }^{\circ} \mathrm{C}$ for $75 \mathrm{~h}$. The resulting solid, 1-butyl-3-methylimidazolium chloride, was thoroughly washed with ethyl acetate $(4 \times 100 \mathrm{~mL}$, at least $)$ and then the remaining volatile compounds were removed by heating to $50{ }^{\circ} \mathrm{C}$ under $0.1 \mathrm{mmHg}$ pressure. To the chloride solution in $300 \mathrm{~mL}$ of water, cooled with an ice-water mixture and vigorously stirred, was added dropwise $160 \mathrm{~g}$ (0.65 mol) of hexafluorophosphoric acid solution (60\%, Aldrich). The lower layer was separated and washed with deionized water until the washings were no longer acidic. The resulting yellowish viscous oil was dissolved in $150 \mathrm{~mL}$ of dichloromethane and purified on a chromatographic column packed with silica gel (15 g, lower) and charcoal (10 g, upper) layers. After removing of dichloromethane on a rotary evaporator, the remaining colorless oil was pumped out $(0.1 \mathrm{mmHg})$ at $50{ }^{\circ} \mathrm{C}$ for $2 \mathrm{~h}$, to give 125 g $(88 \%)$ of 1-butyl-3-methylimidazolium hexafluorophosphate.

2.2. Pulse Radiolysis. Pulse radiolysis experiments were carried out with a high energy (6 MeV) 17 ns electron pulse generated from an ELU-6 linear electron accelerator. The dose absorbed per pulse was determined with an $\mathrm{N}_{2} \mathrm{O}$ saturated aqueous solution of $\mathrm{KSCN}(0.01 \mathrm{M})$, assuming $G\left((\mathrm{SCN})_{2}{ }^{--}\right)=$ 6.0 and $\epsilon\left((\mathrm{SCN})_{2}{ }^{--}\right)=7600 \mathrm{M}^{-1} \mathrm{~cm}^{-1}(G$ represents the yield of radicals per $100 \mathrm{eV}$ of energy absorbed and $\epsilon$ is molar extinction coefficient at $475 \mathrm{~nm}){ }^{30}$ The dose delivered per pulse was within the range 5-80 Gy. Details of pulse radiolysis system are given elsewhere. ${ }^{31}$

The pulse radiolysis of neutral water produces three highly reactive species, $\mathrm{e}_{\mathrm{aq}}(2.6),{ }^{\bullet} \mathrm{OH}(2.7)$, and $\mathrm{H}^{\bullet}(0.6)$, in addition to the formation of less reactive products, $\mathrm{H}_{2} \mathrm{O}_{2}(0.7), \mathrm{H}_{2}(0.45)$, and $\mathrm{H}_{3} \mathrm{O}^{+}$(2.6) (numbers in parentheses are the $G$ values 100 ns after electron pulse).$^{32}$

To study the reaction of $\mathbf{D A}$ with the hydroxyl radicals, the aqueous solutions were saturated with the $\mathrm{N}_{2} \mathrm{O}$ to convert $\mathrm{e}_{\mathrm{aq}}$ into hydroxyl radicals (reaction $2, k=8.7 \times 10^{9} \mathrm{M}^{-1} \mathrm{~s}^{-1}$ ) 33 and to remove oxygen.

$$
\mathrm{e}_{\mathrm{aq}}+\mathrm{N}_{2} \mathrm{O} \rightarrow{ }^{\bullet} \mathrm{OH}+\mathrm{OH}^{-}+\mathrm{N}_{2}
$$

To study the reaction of $\mathbf{D A}$ with $\mathrm{Br}_{2}{ }^{--}$, the pulse radiolysis was carried out in the solution of $\mathrm{KBr}$, so that the ${ }^{\circ} \mathrm{OH}$ radicals react with bromide anions to form dibromide radical anions. ${ }^{33}$ The solution was saturated with $\mathrm{N}_{2} \mathrm{O}$ (see above).

$$
\begin{gathered}
\mathrm{Br}^{-}+{ }^{\bullet} \mathrm{OH} \rightarrow{ }^{\bullet} \mathrm{Br}+\mathrm{OH}^{-} \\
{ }^{\mathrm{Br}}+\mathrm{Br}^{-} \rightarrow \mathrm{Br}_{2}^{\cdot-}
\end{gathered}
$$

The alloxan reduction was observed in the reaction with 2-propanol ketyl radical formed via reactions 5 and 6.

$$
\begin{gathered}
{ }^{\bullet} \mathrm{OH}+\left(\mathrm{CH}_{3}\right)_{2} \mathrm{CHOH} \rightarrow\left(\mathrm{CH}_{3}\right)_{2}{ }^{\bullet} \mathrm{COH}+\mathrm{H}_{2} \mathrm{O} \\
{ }^{\circ} \mathrm{H}+\left(\mathrm{CH}_{3}\right)_{2} \mathrm{CHOH} \rightarrow\left(\mathrm{CH}_{3}\right)_{2}{ }^{\bullet} \mathrm{COH}+\mathrm{H}_{2}
\end{gathered}
$$

The reduction was carried out in aqueous solutions containing 1 M 2-propanol saturated with $\mathrm{N}_{2} \mathrm{O}$. $\alpha$-Hydroxyalkyl radicals formed in reactions 5 and 6 with $85 \%$ yield (the remaining $15 \%$ are unreactive $\beta$-hydroxy radicals) are strongly reducing species that react with many compounds via one-electron transfer $\left(\mathrm{E}^{\circ}\left(\left(\mathrm{CH}_{3}\right)_{2} \mathrm{CO}, \mathrm{H}^{+} /\left(\mathrm{CH}_{3}\right)_{2}{ }^{\circ} \mathrm{COH}\right)=-1.39 \mathrm{~V}\right) .{ }^{33}$ This reduction method was also used in the determination of the $\mathrm{p} K_{\mathrm{a}}$ of enol form of DA radical cation, assuming that the yield of generated radicals does not change within the $\mathrm{pH}$ range used.

The $\mathrm{pH}$ of the solutions was adjusted with perchloric acid or sodium hydroxide and measured with an ORION 420A pH meter (Orion Research, Inc.).

Kinetic analysis was done with the Levenberg-Marquardt algorithm. The first-order rate constant values $\left(k_{\mathrm{obs}}\right)$ were evaluated from the plot of $\Delta A$ vs time. The bimolecular rate constants were determined from the slope of the linear plot of $k_{\mathrm{obs}}$ vs solute concentration.

2.3. Cryogenic Measurements. Glassy samples of the 2-methylterahydrofuran (MTHF), 2-chlorobutane, 1-butyl-3methylimidazolium hexafluorophosphate $\left(\mathrm{BMIM}^{+} \mathrm{PF}_{6}{ }^{-}\right)$or its 1:1 mixture with dichloromethane were prepared by immersing room-temperature solutions in liquid nitrogen. The samples were $0.5-3 \mathrm{~mm}$ thick and were placed in a temperature controlled, liquid nitrogen-cooled cryostat (Oxford Instruments). The desired temperature $(77-150 \mathrm{~K})$ was achieved by automatically adjusted heating. Optical absorption spectra were measured on a Varian Cary 5 spectrometer. The samples mounted in the cryostat were irradiated with $4 \mu$ s electron pulses from the accelerator.

The radiolysis of glassy MTHF leads to the formation of solvated electrons $\left(\mathrm{e}_{\mathrm{s}}^{-}\right)$and the radical cations of solvent molecules (reaction 7).

$$
\mathrm{C}_{5} \mathrm{H}_{10} \mathrm{O} \rightarrow \mathrm{C}_{5} \mathrm{H}_{10} \mathrm{O}^{\bullet+}+\mathrm{e}_{\mathrm{s}}^{-}
$$

The solvated electrons react with the solute molecules (such as alloxan $\mathbf{A}$ ) to give the corresponding radical anions (reaction 8 ), whereas the ionized solvent molecules easily transfer a proton onto neighboring neutral molecules (reaction 9). ${ }^{34}$

$$
\begin{gathered}
\mathrm{e}_{\mathrm{s}}^{-}+\mathbf{A} \rightarrow \mathbf{A}^{\bullet-} \\
\mathrm{C}_{5} \mathrm{H}_{10} \mathrm{O}^{\bullet+}+\mathrm{C}_{5} \mathrm{H}_{10} \mathrm{O} \rightarrow{ }^{\bullet} \mathrm{C}_{5} \mathrm{H}_{9} \mathrm{O}+\mathrm{C}_{5} \mathrm{H}_{11} \mathrm{O}^{+}
\end{gathered}
$$

The products of this latter process can act as acids or as proton donors. ${ }^{34,35}$ Under matrix conditions these bimolecular reactions are, however, largely suppressed. They can be observed only upon softening of a matrix on its annealing.

For the generation of radical cations solutions of the dialuric acid in alkyl halides (2-chlorobutane was used in this work) are preferred, as these solvents dissociatively capture electrons ejected from the solvent molecules, whereas the positive charge is transferred to solute molecules of lower ionization potential. ${ }^{34}$ 


\section{SCHEME 1}
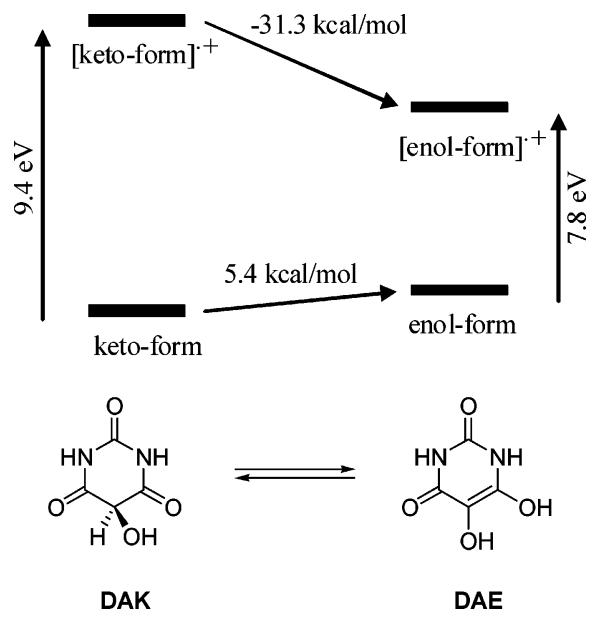

Glassy matrixes of 1-butyl-3-methylimidazolium hexafluorophosphate were used for the same purpose, as the ionic liquid environment is suitable for radical cations generation. We have shown previously that ionic liquids can be used as a novel media for characterization of radical ions because many of them form transparent, good quality glasses on freezing at $77 \mathrm{~K} .{ }^{36}$ Recently, we have found that the glass quality does not change upon addition of some organic component to the ionic liquid. For example, a 1:1 mixture of $\mathrm{BMIM}^{+} \mathrm{PF}_{6}{ }^{-}$and $\mathrm{CH}_{2} \mathrm{Cl}_{2}$ formed a transparent glass. A few important effects can be achieved with such a mixture: first, the better solubility of some compounds and, second, a higher yield of radical cation generation because $\mathrm{CH}_{2} \mathrm{Cl}_{2}$ molecules dissociatively capture electrons.

2.4. Quantum Chemical Calculations. The geometries of all species were optimized by the B3LYP density functional method ${ }^{37}$ as implemented in the Gaussian 03 suite of programs. ${ }^{38}$ The above calculations were done at the B3LYP/6-31G* level. Relative energies, including ZPE corrections, were calculated at the same level. In addition, a transition state was characterized by full intrinsic reaction coordinate (IRC) calculations.

Electronic transitions were predicted by density functionalbased time-dependent response theory. ${ }^{39} \mathrm{We}$ used the formulation of TD-DFT implemented in the Gaussian 03 program, ${ }^{40}$ together with the B3LYP functional and the $6-31 \mathrm{G}^{*}$ basis set.

\section{Results and Discussion}

The structures of dialuric acid in keto (DAK) and enol (DAE) forms were determined by B3LYP/6-31G* density-functional calculations. The above B3LYP calculations also yielded the energetics of the keto-enol tautomerization. Thus, enolization is endothermic by around $5.4 \mathrm{kcal} / \mathrm{mol}$ in the neutral compound, whereas it becomes exothermic by about $31.3 \mathrm{kcal} / \mathrm{mol}$ in the radical cation (Scheme 1). As a consequence of the abovementioned inversion of stability order of tautomers, it is much easier to ionize the enol form than the keto form. In the case of dialuric acid, the ionization is facilitated by almost $1.6 \mathrm{eV}(36.8$ $\mathrm{kcal} / \mathrm{mol}$ ) upon enolization of DA molecule.

Dialuric acid is poorly soluble in organic solvents used commonly to form low-temperature glasses. In experiments where radical ions are generated by radiolytic reduction or oxidation in solid matrixes, the concentration of solute molecules must be at least $10^{-3} \mathrm{M}$ or higher to ensure efficient scavenging of the initially generated electrons or holes. Poor solubility of the solute may therefore represent a significant obstacle.

A little better solubility of this product can be obtained if experiments are done in ionic liquid glasses. We have shown

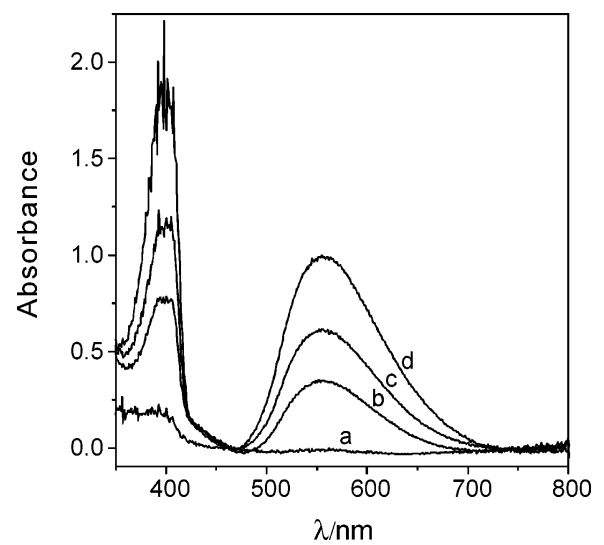

Figure 1. Electronic absorption spectrum obtained on radiolysis of dialuric acid DA embedded in $\mathrm{BMIM}^{+} \mathrm{PF}_{6}{ }^{-}$glass at (a) $77 \mathrm{~K}(2 \mathrm{mM}$ solution, radiation dose $2.8 \mathrm{kGy}$, optical path $2 \mathrm{~mm}$ ) and the subsequent changes of the spectrum observed upon matrix annealing at (b) $135 \mathrm{~K}$ for $50 \mathrm{~min}$, (c) $140 \mathrm{~K}$ for $60 \mathrm{~min}$, and (d) $150 \mathrm{~K}$ for $40 \mathrm{~min}$.

previously that these novel solvents, many of which from stable transparent glasses at $77 \mathrm{~K},{ }^{36}$ can be used for radical ions generation by radiolysis. An important feature of such glasses is the observation that, even at low concentration of the solute, the good quality spectra of the radical cations can be observed without noticeable interference from the radiolysis byproducts.

The initial spectrum of the irradiated matrix containing dialuric acid shows no transient absorption in the visible or NIR. However, annealing of the matrix causes a significant growth of the absorption bands at 560 and $400 \mathrm{~nm}$ (see spectra in Figure 1). No other transient products were distinguished in the spectrum even upon prolongated annealing of the matrix. The delayed formation of the transient species upon ionization of DA embedded in the matrix raised the question whether the observed spectrum can be assigned to the primary product of radiolysis, i.e., dialuric acid radical cation, or to the product of its rearrangement or intermolecular reaction.

According to DFT calculations it might be expected that under matrix conditions dialuric acid exists mainly in the keto form, because the difference in the relative energies of both tautomeric forms is above $5 \mathrm{kcal} / \mathrm{mol}$. Therefore the radical cation of DA in the keto form should be formed exclusively unless the solvation effect shifts the equilibrium toward the enol form. Under matrix conditions solute molecules of lower ionization potential (IP) could be ionized preferentially over the solute components present at higher concentration, but of higher IP. It could be expected that even a small shift in the keto-enol equilibrium could result in the preferential formation of the enol radical cation.

On the other hand, it is well documented that many of the intramolecular processes with high activation barriers proceed extremely slowly under matrix conditions. For example, it is possible under favorable circumstances to observe spontaneous enolization of molecules ionized under matrix conditions, due to the reversal of relative stabilities of tautomers. Such favorable circumstances prevail, for example, in 1,5-hydrogen transfers proceeding via six-membered ring transition states, as they occur in compounds with aromatic rings carrying an alkyl group adjacent to a carbonyl unit, e.g., in $o$-carbonyl toluenes. Because radical cations do not profit from the aromatic resonance energy stabilization, the exothermicity of their enolization is similar to that of simple ketone radical cations, and the process is observed even in the low-temperature matrixes. ${ }^{28,29}$ We have recently attempted to apply a concept of radical cation tautomerization also to nicotinamide derivatives and we concluded that, in the 
case of NADH derivatives, where the keto-enol tautomerization involves a 1,4-hydrogen atom shift, this process is associated with a relatively high activation barrier, but still it could proceed effectively in radical cations, which can assume a favorable geometry. ${ }^{41,42}$ Increase of the matrix temperature significantly accelerated such processes.

Moreover, annealing of the matrix softens the rigid environment of the embedded molecule and in the case of intramolecular processes which require some extensive structural changes this may additionally favor the process. For example, such structural changes of the dialuric acid ring are also expected upon enolization. In the enol form, the pyrimidine ring remains planar in contrast to the puckered structure of the keto form.

Finally, an annealing of the matrix above its glassy transition temperature also gradually abolishes the inhibitory effect of the rigid matrix on intermolecular processes. The primary reaction, characteristic to the radical cations in either keto or enol form, would be their deprotonation because these species are usually characterized by very low $\mathrm{p} K_{\mathrm{a}}$ values. ${ }^{42,43}$ All the more the primary product of such deprotonation, the semiquinone radical intermediate $\left(\mathbf{A H}^{\bullet}\right)$, was previously characterized by HoueeLevin et al. as a quite stable transient species. ${ }^{23,24}$

In fact, the $\mathbf{A H}^{\bullet}$ radical was the only product observed upon oxidation of dialuric acid in aqueous solution under neutral or slightly acidic conditions. As an oxidant we have used the<smiles>C[13C](=O)[O-]</smiles><smiles></smiles>

dibromide radical anion $\left(\mathrm{Br}_{2}{ }^{--}\right)\left(E^{\circ}\left(\mathrm{Br}_{2}{ }^{--} / 2 \mathrm{Br}^{-}\right)=1.63 \mathrm{~V}\right.$ vs $\mathrm{NHE}),{ }^{33}$ which is strong enough for the generation of the radical cation of dialuric acid under aqueous conditions. As shown in the Experimental Section, $\mathrm{Br}_{2}{ }^{\bullet-}$ radical anions can be effectively generated by pulse radiolysis of aqueous solutions containing $\mathrm{KBr}$. Unfortunately, $\mathrm{Br}_{2}{ }^{--}$absorbs $\left(\lambda_{\max }=360 \mathrm{~nm}\right)$ in the region of the transient absorption of the species generated from the dialuric acid. The result of this experiment is depicted in Figure 2. Faster decay of the strong $360 \mathrm{~nm}$ absorption band of $\mathrm{Br}_{2}{ }^{--}$ in the presence of the dialuric acid demonstrated that dialuric acid was oxidized by the $\mathrm{Br}_{2}{ }^{--}$radical anion. The rate constant for this fast reaction was estimated as $k=2.5 \times 10^{9} \mathrm{M}^{-1} \mathrm{~s}^{-1}$, which is not unusual for the dibromide radical anion. ${ }^{33}$ The spectrum of $\mathrm{Br}_{2}{ }^{--}$was then replaced by a weaker band above $350 \mathrm{~nm}$ accompanied by an elevated absorption at shorter wavelengths.

To confirm that the spectrum of this new product was not affected by the residual absorption of $\mathrm{Br}_{2}{ }^{--}$, we have used hydroxyl radicals as an oxidizing species (or hydrogen atom acceptor). The formation of the transient species was observed also in this case and its spectrum closely resembles that of the semiquinone radical, $\mathbf{A H}^{\bullet}$ (see Figure 3). The rate constant for the reaction of $\mathbf{D A}$ with ${ }^{\circ} \mathrm{OH}\left(k=1.5 \times 10^{8} \mathrm{M}^{-1} \mathrm{~s}^{-1}\right)$ was determined on the basis of the $\mathbf{A H}^{\bullet}$ formation. It is very likely that because of the short lifetime of the dialuric radical cation in solution no evidence for its presence was found. In contrast

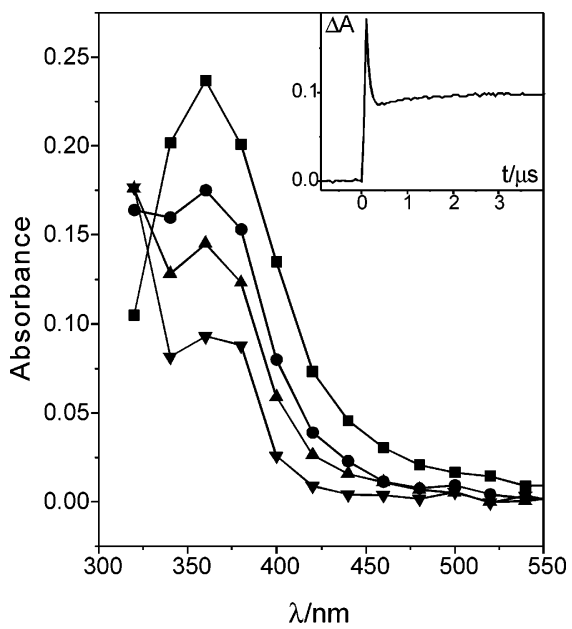

Figure 2. Transient absorption spectra obtained by pulse radiolysis of DA $(5 \mathrm{mM})$ in $\mathrm{N}_{2} \mathrm{O}$ saturated aqueous solution containing $0.1 \mathrm{M}$ $\mathrm{KBr}$. The spectra were collected (Ш) $30 \mathrm{~ns},(\bullet) 80 \mathrm{~ns},(\boldsymbol{\Delta}) 0.1 \mu \mathrm{s}$ and ( $\mathbf{\nabla}) 0.25 \mu$ s after the electron pulse. Inset: changes of absorbance at $360 \mathrm{~nm}$. The sample was $1 \mathrm{~cm}$ thick and received a radiation dose of 60 Gy.

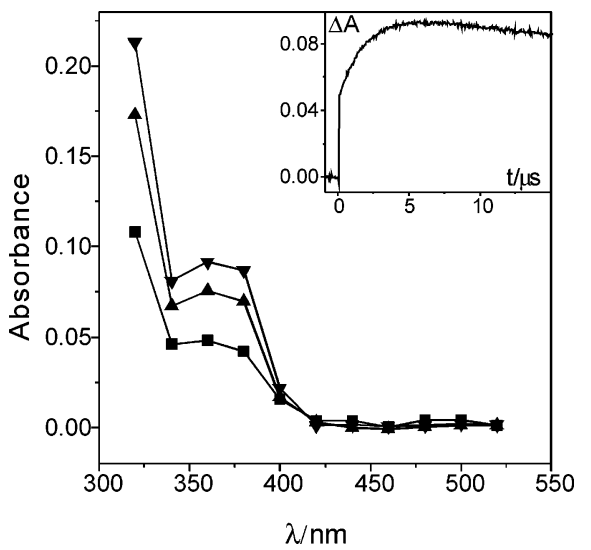

Figure 3. Transient absorption spectra of products of the reaction of DA with hydroxyl radicals. Spectra obtained (ם) $0.1 \mu \mathrm{s},(\mathbf{\Delta}) 1.5 \mu \mathrm{s}$ and $(\boldsymbol{\nabla}) 4 \mu$ s after the pulse radiolysis of DA aqueous solution saturated with $\mathrm{N}_{2} \mathrm{O}$. Inset: changes of absorbance at $360 \mathrm{~nm}$. (DA concentration $=5 \mathrm{mM}$, radiation dose $=60 \mathrm{~Gy}$, optical path $=1 \mathrm{~cm}$ ).

the radical decayed rather slowly, $2 \mathrm{k} / \epsilon l=1.3 \times 10^{5} \mathrm{~s}^{-1}$, through the disproportionation reaction leading to alloxan and dialuric acid. $^{23,24}$

We characterized the spectrum of the radical also under matrix conditions. The optical spectrum obtained on pulse radiolysis of a solution of alloxan in a glass of 2-methyltetrahydrofuran at $77 \mathrm{~K}$ (see Figure 4) is composed of a strong band peaking at $650 \mathrm{~nm}$, accompanied by bands at shorter wavelengths, at 380 $\mathrm{nm}$ (strong) and $440 \mathrm{~nm}$ (weak). The above spectrum must be ascribed to $\mathbf{A}^{\bullet-}$. This elusive species (not observed as a transient in pulse radiolysis experiments in aqueous solution) decayed upon slight annealing of the matrix, and was replaced by the spectrum with the absorption band at $380 \mathrm{~nm}$ (with a shoulder at $420 \mathrm{~nm}$ ), which can be assigned to the semiquinone radical, $\mathbf{A H}^{\bullet}$. Although MTHF is an aprotic solvent, the positive ions, $\mathrm{C}_{5} \mathrm{H}_{11} \mathrm{O}^{+}$, that are generated on irradiation of the matrix (see Experimental Section) may act as proton donors. Such protonation of radical anions to their ketyl radicals is welldocumented, for example, for benzophenone and acetophenone radical anions on annealing of the irradiated MTHF matrix. ${ }^{22,39}$

It is very likely that radical absorption participates to some extent already to the initial spectrum presented in Figure 4. Because of the high concentration of DA $(0.01 \mathrm{M})$ used in this 


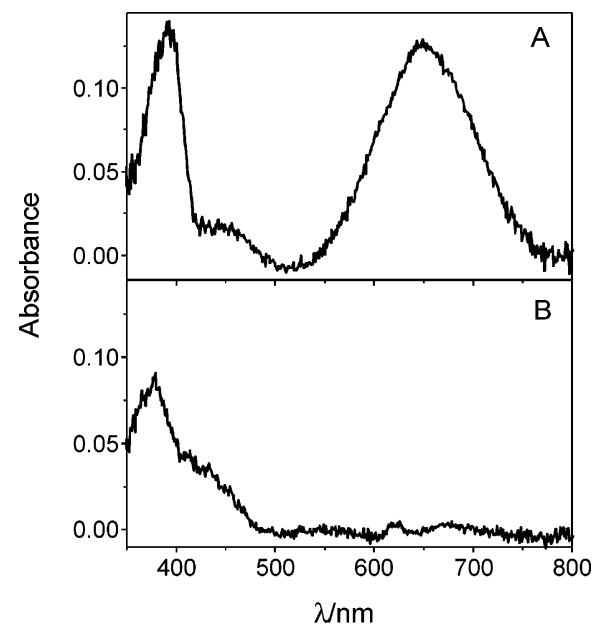

Figure 4. Absorption spectrum obtained on radiolysis of alloxan in MTHF matrix (A) at $77 \mathrm{~K}$ and (B) upon matrix annealing for $60 \mathrm{~min}$ at $95 \mathrm{~K}(0.01 \mathrm{M}$, radiation dose $2.7 \mathrm{kGy}$, optical path $2 \mathrm{~mm})$.

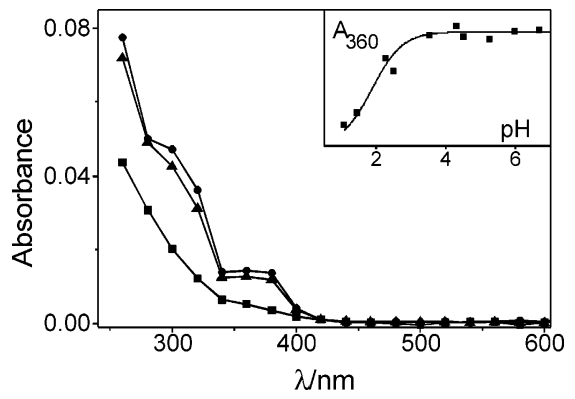

Figure 5. Transient absorption spectra observed upon pulse radiolysis of alloxan $(5 \mathrm{mM})$ in aqueous solution $\left(\mathrm{N}_{2} \mathrm{O}\right.$, 2-propanol [1 $\left.\left.\mathrm{M}\right]\right)$; spectra collected $1 \mu$ s after a $17 \mathrm{~ns}$ pulse at $\mathrm{pH} 7(\mathbf{\bullet}), \mathrm{pH} 4(\boldsymbol{\nabla})$ and $\mathrm{pH} 1(\mathbf{\square})$. Dose $=60 \mathrm{~Gy}$, thickness of the samples $=1 \mathrm{~cm}, T=25^{\circ} \mathrm{C}$. Inset: absorption (arbitrary units) at $360 \mathrm{~nm}$ (after $1 \mu \mathrm{s}$ ) vs $\mathrm{pH}$.

experiment, the radical absorption bands at shorter wavelengths could not be observed. It is evident from the above presented results that the spectrum observed in ionic liquid glass cannot be assigned to the semiquinone radical but rather to the radical cation in either keto or enol form.

Reduction of alloxan in aqueous solution containing $1 \mathrm{M}$ 2-propanol at neutral or slightly acidic conditions gave the transient spectrum of $\mathbf{A} \mathbf{H}^{\bullet}$, presented in Figure 5, without the<smiles>[CH2-][NH2+]C(=O)N1C(=O)NC(=O)C(=O)C1=O</smiles>

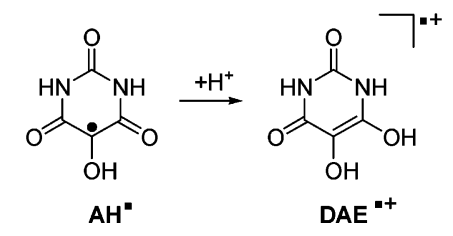

observation of the primary product, alloxan radical anion $\mathbf{A}^{\mathbf{}^{-}}$. At acidic conditions the radical spectrum, however, vanished. No new absorption bands above $350 \mathrm{~nm}$ were formed although it might be expected that under acidic conditions an appropriate dialuric acid radical cation should be formed upon protonation of the radical. Assuming that yield of generated radicals does not change within the $\mathrm{pH}$ range used, the $\mathrm{p} K_{\mathrm{a}}=1.5-2$ of this acid-base equilibrium was estimated. Because the protonation
TABLE 1: Lowest Excited States of Keto and Enol Radical Cations of Dialuric Acid by TD-B3LYP Calculations

\begin{tabular}{|c|c|c|c|c|c|c|c|}
\hline \multicolumn{2}{|c|}{$\mathrm{EAS}^{a}$} & \multicolumn{3}{|c|}{$\mathrm{DAK}^{\bullet+}$} & \multicolumn{3}{|c|}{$\mathrm{DAE}^{\bullet+}$} \\
\hline $\mathrm{nm}$ & $\mathrm{eV}$ & $\mathrm{nm}$ & $\mathrm{eV}$ & $f^{b}$ & $\mathrm{~nm}$ & $\mathrm{eV}$ & $f^{b}$ \\
\hline $\begin{array}{l}560 \\
400\end{array}$ & $\begin{array}{l}2.21 \\
3.10\end{array}$ & $\begin{array}{l}694 \\
625 \\
424\end{array}$ & $\begin{array}{l}1.77 \\
1.98 \\
2.92\end{array}$ & $\begin{array}{l}0.02 \\
0.09 \\
0.03\end{array}$ & 497 & 2.49 & 0.01 \\
\hline & & & & & $\begin{array}{l}342 \\
280\end{array}$ & $\begin{array}{l}3.63 \\
4.43\end{array}$ & $\begin{array}{l}0.05 \\
0.08\end{array}$ \\
\hline
\end{tabular}

${ }^{a}$ EAS: electronic absorption spectrum. ${ }^{b}$ Oscillator strength for electronic transition.

of the radical leads to the radical cation and because the radical cation in the keto form, $\mathbf{D A K} \mathbf{K}^{+}$, which is obtained by protonation at C-5, is less stable than the corresponding enol form, $\mathbf{D A E}^{\cdot+}$, which arises upon protonation of the carbonyl function, it is reasonable to assume that the latter is being formed predominantly.

To confirm the above assignment, we performed the timedependent density functional response theory TD-B3LYP calculations for the related enol and keto radical cations, $\mathbf{D A E} \mathbf{E}^{\bullet+}$ and $\mathbf{D A K}^{\bullet+}$ (see Table 1).

In the visible spectrum, TD-B3LYP predicted a much more intense transition of the keto form, $\mathbf{D A K} \mathbf{K}^{\bullet}$, than of the enol form, $\mathbf{D A E}^{\bullet+}$. In the latter case, besides a very weak absorption band around $500 \mathrm{~nm}$, which might remain undetected in the pulse radiolysis transient spectrum presented in Figure 5, stronger absorption bands are expected below $350 \mathrm{~nm}$. In fact, the spectrum of the radical under strong acidic conditions showed a strong rise toward the UV end of the spectra, which suggested the presence of intense bands of the radical cation below $350 \mathrm{~nm}$, in agreement with the TD-B3LYP prediction for $\mathbf{D A E} \mathbf{E}^{\bullet+}$.

According to TD-DFT the absorption of $\mathbf{D A K}^{\bullet+}$ in the visible spectrum should be about 9 times greater than that of $\mathbf{D A E}{ }^{\bullet+}$. It becomes evident from Table 1 that the spectrum observed in the ionic liquid glass stays in good agreement with TD-B3LYP results for $\mathbf{D A K}{ }^{\bullet+}$, which predict a strong absorption at $\lambda_{\max }=$ $625 \mathrm{~nm}$, preceded by a 4-5 times weaker one at $694 \mathrm{~nm}$ (which could be responsible for the long-wavelength shoulder and/or asymmetry of the visible band). The next transition was predicted at $424 \mathrm{~nm}$, i.e., where the experimental spectrum possessed strong band peaking at $400 \mathrm{~nm}$. It is also interesting to note that all electronic transitions in the visible range of radical cations of both forms involve excitation to the singly occupied molecular orbital (SOMO) from lower-lying doubly occupied orbitals.

It is therefore reasonable to assign the spectrum from Figure 1 to the dialuric acid in the keto form. The lowest energy pathway for the tautomerization of the dialuric acid radical cation involves a 1,3 hydrogen shift through the transition state with a hydrogen atom almost in the halfway between its positions in the keto and enol structures. The B3LYP intrinsic reaction coordinate (IRC) calculation revealed that a high activation barrier $(45 \mathrm{kcal} / \mathrm{mol})$ can be expected for this process. Therefore the formation of an enol form in the intramolecular process is very unlikely, unless assisted by external proton donors/acceptors. It is evident from the DFT results that the unpaired spin in $\mathbf{D A K}{ }^{\bullet+}$ is mainly located onto the oxygen atoms of the side carbonyl groups. They might therefore become a primary target for the intermolecularly assisted deprotonationreprotonation reactions. ${ }^{43}$

Retarded formation of $\mathbf{D A K} \mathbf{K}^{\bullet+}$ under matrix conditions, as presented in Figure 1, must be therefore explained on the basis of the poor solubility of DA. Solubility of dialuric acid in 


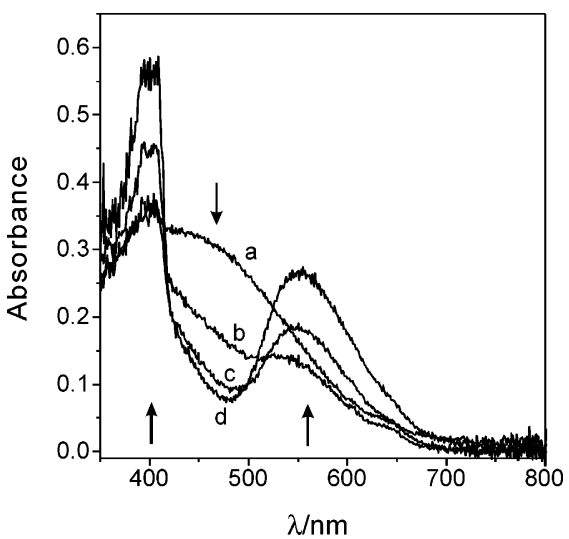

Figure 6. Electronic absorption spectrum obtained on radiolysis of dialuric acid DA embedded in $\mathrm{BMIM}^{+} \mathrm{PF}_{6}{ }^{-}: \mathrm{CH}_{2} \mathrm{Cl}_{2}$ (1:1) glass at (a) $77 \mathrm{~K}$ ( $3 \mathrm{mM}$ solution, radiation dose $2.8 \mathrm{kGy}$, optical path $2 \mathrm{~mm}$ ) and the subsequent changes of the spectrum observed upon matrix annealing at (b) $115 \mathrm{~K}$ for $30 \mathrm{~min}$, (c) $120 \mathrm{~K}$ for $30 \mathrm{~min}$ and (d) $130 \mathrm{~K}$ for $30 \mathrm{~min}$.

imidazolium ionic liquids is limited to $2 \times 10^{-3} \mathrm{M}$. In the case of a low concentration of solute molecules embedded in rigid matrixes, it is often observed that long-range electron transfer is completely or at least partially hindered, especially in cases of solutes of relatively high ionization potentials, such as dialuric acid in the keto form. However, it could be restored, at least to some extent, upon matrix softening and liberation of the diffusion of matrix hole carriers and solute molecules. Therefore in an ionic liquids environment, ionization of dialuric acid is not observed till matrix softening.

In contrast to the experiments from glassy ionic liquids, a similar process was not observed in the 2-chlorobutane matrix, although the solubility of DA remained very similar. It is, however, well recognized that in this matrix initially formed radical cations of the 2-chlorobutane easily rearrange upon matrix softening to the butene radical cations incapable of ionizing the dialuric acid because of their low ionization potential. $^{44}$

Recently we have found that the glass quality does not change upon addition of an organic component to the ionic liquid. For example, 1:1 mixtures of the 1-butyl-3-methylimidazolium hexafluorophosphate and $\mathrm{CH}_{2} \mathrm{Cl}_{2}$ form a transparent glass. Not only does $\mathrm{CH}_{2} \mathrm{Cl}_{2}$ improve the solubility of many precursors, but it also leads to a higher yield of radical cations on radiolysis due to its ability to scavenge electrons by dissociative attachment. ${ }^{45}$ In such a matrix the initial spectrum characterizes itself by a broad structureless absorption band at $470 \mathrm{~nm}$, which can be assigned to the matrix hole (ionized methylene chloride) or its charge-transfer complexes with the ionic environment, because it was also observed without any solute added. ${ }^{45,46}$ When the matrix is annealed, the bands assigned to the $\mathbf{D A K} \mathbf{K}^{\bullet+}$ grow in a manner similar to that discussed above, at the expense of the $470 \mathrm{~nm}$ band (see Figure 6). Therefore it can be concluded that the delayed formation of $\mathbf{D A K} \mathbf{K}^{\bullet+}$ is directly related to the radical cation formation (hole transfer process) retarded by the low concentration of the dialuric acid and its relatively high ionization potential.

\section{Conclusions}

In contrast to the dialuric acid in the keto form, it is the enol form of the compound that should be easily susceptible to the auto-oxidation process and hence formation of superoxide radical anion and subsequent reactive oxygen species likely responsible for the alloxan toxic action. Facilitation of the one-

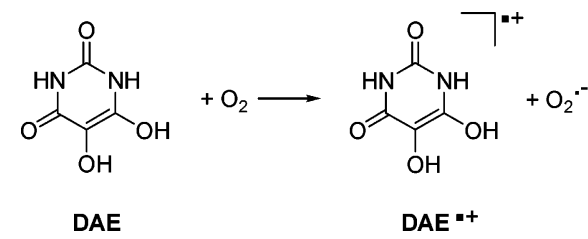

electron oxidation of the dialuric acid upon its enolization results from the inversion of stability order of molecules on ionization. The present study does not provide any definite answers to the importance of this phenomenon upon physiological conditions. Both neutral keto and enol forms are, however, energetically close, and under favorable conditions, the auto-oxidation of dialuric acid could proceed via the enol form of dialuric acid.

The observed effective formation of ROS in intracellular processes suggests participation of superoxide radical anion formed upon auto-oxidation and this process seems to involve an easily oxidized species as the enol form of dialuric acid.

In this paper we present evidence for the formation of radical cations in both forms. The spectrum of $\mathbf{D A K}{ }^{\bullet+}$ was observed in ionic liquid glasses upon direct ionization of the compound, whereas the $\mathbf{D A E}^{\bullet+}$ was formed upon protonation of semiquinone radical $\mathbf{A H}^{\bullet}$ via a sequential electron-proton-proton attachment to alloxan under acidic aqueous condition. Because the keto radical cations $\mathbf{D A K} \mathbf{K}^{\bullet+}$ that are obtained by protonation at C-5 are less stable than the corresponding enol form $\mathbf{D A E} \mathbf{E}^{+}$ which arise upon O-protonation of the radical, it is reasonable to assume that the latter are being formed predominantly. Indeed, the TD-B3LYP calculation provides some additional support to those experimental findings. The high activation barrier for the tautomerization process indicated by the B3LYP explains the absence of the intramolecular enolization under matrix conditions, although we cannot exclude the possibility that this process might be effective with the assistance of proton donors/ acceptors.

Acknowledgment. This work was supported by the grant (No. 4/T09A/020/24) from the Ministry of Science and Informatization.

\section{References and Notes}

(1) Rerup, C. C. Pharmacol. Rev. 1970, 22, 485.

(2) Oberley, L. W. Free Radical Biol. Med. 1988, 5, 113.

(3) Heikkila, R. E.; Winston, B.; Cohen, G. Biochem. Pharmacol. 1976, 25,1085

(4) Deamer, D. W.; Heikkila, R. E.; Panganamala, R. V.; Cohen, G.; Cornwell, D. G. Physiol. Chem. Phys. Med. NMR 1971, 3, 426.

(5) Cohen, G.; Heikkila, R. E. J. Biol. Chem. 1974, 249, 2447.

(6) Malaisse, W. J. Biochem. Pharmacol. 1982, 31, 3527.

(7) Munday, R. Biochem. Pharmacol. 1988, 37, 409.

(8) Winterbourn, C. C.; Cowden, W. B.; Sutton, H. C. Biochem Pharmacol. 1989, 38, 611. 271.

(9) Winterbourn, C. C.; Munday, R. Biochem. Pharmacol. 1989, 38,

(10) Lenzen S.; Munday R. Biochem. Pharmacol. 1991, 42, 1385.

(11) Brömme, H.-J.; Ebelt, H.; Peschke, D.; Peschke, E. Cell. Mol. Life Sci. 1999, 55, 487.

(12) Sakurai, K.; Ogiso, T. Chem. Pharm. Bull. 1991, 39, 737.

(13) Nukatsuka, M.; Sakurai, H.; Kawada, J. Biochem. Biophys. Res. Commun. 1989, 165, 278.

(14) Holmgren, A.; Lyckeborg, C. Proc. Natl. Acad. Sci. U.S.A. 1980, 77,5149 .

(15) Washburn, M. P.; Wells, W. W. Free Radical Biol. Med. 1997, 23,563 .

(16) Miwa, I.; Okuda J. Biochem. Pharmacol. 1982, 31, 921.

(17) Grankvist, K.; Marklund, S. L.; Täljedal, I.-B. Biochem. J. 1981, 199, 393.

(18) Malaisse, W. J.; Malaisse-Lagae, F.; Sener, A.; Pipeleers, D. G. Proc. Natl. Acad. Sci. U.S.A. 1982, 79, 927.

(19) Jörns, A.; Tiedge, M.; Lenzen, S.; Munday, R. Free Radical Biol. Med. 1999, 26, 1300 . 
(20) Houee-Levin, C.; Gardes-Albert, M.; Ferradini, C.; Pucheault, J. Radiat. Res. 1981, 88, 20.

(21) Lagercrantz, C.; Yhland, M. Acta Chem. Scand. 1963, 17, 1677.

(22) Murata, M.; Imada, M.; Inoue, S.; Kawanishi, S. Free Radical Biol. Med. 1998, 25, 586.

(23) Houee-Levin, C.; Gardes-Albert, M.; Ferradini, C.; Pucheault, J. Biochem. Biophys. Res. Commun. 1979, 91, 1196.

(24) Houee-Levin, C.; Gardes-Albert, M.; Ferradini, C.; Pucheault, J. Radiat. Res. 1980, 83, 270.

(25) Fischer, L. J.; Hamburger, S. A. Diabetes 1980, 29, 213.

(26) Uchigata, Y.; Yamamoto, H.; Kawamura, A.; Okamoto, H. J. Biol. Chem. 1982, 257, 6084.

(27) Sentman, M.-L.; Jonsson, L. M.; Marklund, S. L. Free Radical Biol. Med. 1999, 27, 790 .

(28) Schmittel, M. Top. Curr. Chem. 1994, 169, 183.

(29) (a) Marcinek, A.; Michalak, J.; Rogowski, J.; Tang, W.; Bally, T.; Gębicki, J. J. Chem. Soc., Perkin Trans. 2 1992, 1353. (b) Gȩbicki, J.; Bally, T. Acc. Chem. Res. 1997, 30, 477.

(30) Schuler, R. H.; Patterson, L. K.; Janata, E. J. Phys. Chem. 1980, $84,2088$.

(31) (a) Karolczak, S.; Hodyr, K.; Łubis, R.; Kroh, J. J. Radioanal. Nucl. Chem. 1986, 101, 177. (b) Karolczak, S.; Hodyr, K.; Połowiñski, M. Radiat Phys. Chem. 1992, 39, 1.

(32) Buxton, G. V.; Greenstock, C. L.; Helman, W. P.; Ross, A. B. J. Phys. Chem. Ref. Data 1988, 17, 513.

(33) (a) Neta, P.; Huie, R. E.; Ross, A. B. J. Phys. Chem. Ref. Data 1988, 17, 1027. (b) Wardman, P. J. Phys. Chem. Ref. Data 1989, 18, 1637.

(34) Shida, T. Electronic Absorption Spectra of Radical Ions; Elsevier: Amsterdam, 1988.

(35) Hayon, E.; Ibata, T.; Lichtin, N. N.; Simic, M. J. Phys. Chem. 1972, 76, 2072.

(36) Marcinek, A.; Zielonka, J.; Gȩbicki, J.; Gordon, C. M.; Dunkin, I.

R. J. Phys. Chem. A 2001, 105, 9305.

(37) (a) Becke, A. D. J. Chem. Phys. 1993, 98, 5648. (b) Lee, C.; Yang, W.; Parr, R. G. Phys. Rev. B 1988, 37, 785.
(38) Frisch, M. J.; Trucks, G. W.; Schlegel, H. B.; Scuseria, G. E.; Robb, M. A.; Cheeseman, J. R.; Montgomery, J. A.; Vreven, T.; Kudin, K. N.; Burant, J. C.; Millam, J. M.; Iyengar, S. S.; Tomasi, J.; Barone, V.; Mennucci, B.; Cossi, M.; Scalmani, G.; Rega, N.; Petersson, G. A.; Nakatsuji, H.; Hada, M.; Ehara, M.; Toyota, K.; Fukuda, R.; Hasegawa, J.; Ishida, M.; Nakajima, T.; Honda, Y.; Kitao, O.; Nakai, H.; Klene, M.; Li, X.; Knox, J. E.; Hratchian, H. P.; Cross, J. B.; Adamo, C.; Jaramillo, J.; Gomperts, R.; Stratmann, R. E.; Yazyev, O.; Austin, A. J.; Cammi, R.; Pomelli, C.; Ochterski, J. W.; Ayala, P. Y.; Morokuma, K.; Voth, G. A.; Salvador, P.; Dannenberg, J. J.; Zakrzewski, V. G.; Dapprich, S.; Daniels, A. D.; Strain, M. C.; Farkas, O.; Malick, D. K.; Rabuck, A. D.; Raghavachari, K.; Foresman, J. B.; Ortiz, J. V.; Cui, Q.; Baboul, A. G.; Clifford, S.; Cioslowski, J.; Stefanov, B. B.; Liu, G.; Liashenko, A.; Piskorz, P.; Komaromi, I.; Martin, R. L.; Fox, D. J.; Keith, T.; Al-Laham, M. A.; Peng, C. Y.; Nanayakkara, A.; Challacombe, M.; Gill, P. M. W.; Johnson, B.; Chen, W.; Wong, M. W.; Gonzalez, C.; Pople, J. A. Gaussian 03, revision B.01; Gaussian, Inc.: Pittsburgh, 2003.

(39) Casida, M. E. Time-Dependent Density Functional Response Theory for Molecules. In Recent Advances in Density Functional Methods, part I; Chong, D. P., Ed.; World Scientific: Singapore, 1995; p 155.

(40) Stratmann, R. E.; Scuseria, G. E.; Frisch, M. J. J. Chem. Phys. 1998, 109, 8218 .

(41) Marcinek, A.; Adamus, J.; Huben, K.; Gębicki, J.; Bartczak, T. J.; Bednarek, P.; Bally, T. J. Am. Chem. Soc. 2000, 122, 437. 379 .

(42) Gȩbicki, J.; Marcinek, A.; Zielonka, J. Acc. Chem. Res. 2004, 37,

(43) Marcinek, A.; Rogowski, J.; Adamus, J.; Gębicki, J.; Bednarek, P.; Bally, T. J. Phys. Chem. A 2000, 104, 718.

(44) Arai, S.; Kira, A.; Imamura, M. J. Phys. Chem. 1976, 80, 1968.

(45) Alfassi, Z. B.; Mosseri, S.; Neta, P. J. Phys. Chem. 1989, 93, 1380.

(46) Andrews, 1.; Prochaska, F. T.; Ault, B. S. J. Am. Chem. Soc. 1979, $101,9$. 